unhappy patient to an extra quantity of pommelling and exposure (and they have enough as it is) by the physician himself. As to the fact of the present clerk keeping Dr. Hope's book, having previously had Dr. Macleod's, the reason is plain : no one else wished to take it. Every one who knows anything of his profession at all, is aware that women injure themselves by tight lacing; it will be useless, therefore, to comment on the remarks on that subject in the letter of your correspondent.

Another Medical Student.

\section{HANWELL ASYLUM.}

\section{To the Editor of The LANCET.}

SrR:-I have read the two letters signed "Philanthropos," in your Numbers of the 20 th and 27 th of February, and which I presume are from the pen of one of the visiting justices of the Hanwell Lunatic Asylum. I have neither time nor inclination to enter into discussions with an anonymous opponent; neither do I think it necessary, after the full and public defence of my conduct, voluntarily undertaken, in $\mathrm{my}$ absence, by $M_{r}$. Sergeant Halcombe, and other magistrates, at the late meetings of the Middlesex justices upon this subject, and to whom I beg leave to return my most grateful thanks. I understand that, in result, it was the almost universal opiniou of the court, that farther inquiry must take place into the medical treatment, and the so-called system of non-restruint, pursued at Hanwell; of the result of which inquiry I entertain not the slightest doubt, and shall, therefore, trouble you no further in the present state of this subject. I am, Sir, your most obedient servant,

Dorset County Lunatic Asylum.

\section{PRURITUS ANI FROM ASCARIDES.}

To the Editor of ThE CANCET.

SIR :-Lime-water has long been a popular remedy in vermination, and could we secure its direct contact with the worms in every case it would be an infallible one. Let anybody who doubts this pour a small quantity of lime-water upon a grass-plot, and observe the effect upon the lumbrici, the rapidity with which they shoot to the surface and die. An accidental observation of this phenomenon led me to employ enemata of lime-water in ascarides, and I recommend J. H. to try them in the case he alludes to. The remedy is exceedingly simple, and he may prescribe it on any return of the nuisance. As quantities of the entozoa are expelled by it on each application, I imagine he would in time get rid of them altogether. I have generally preceded it with a purgative of calomel and rhubarb.
Medical-Board Examinations.-A cor. respondent (Ediuburgh) warmly complains of " certain persons who denominate then. selves lecturers, and who are qualified to instruct the young, but who endeavour to entrap the student, by informing him that their class-tickets will qualify them for ad. mission to examination by the Naval and other public boards; and thus induce the student, at a distance from his friends and advisers, to pay the fees for a ticket which afterwards proves to be of no such use to him. Both I," he adds, "and fellow. students have experienced this deceit from individuals, in whom all confidence has been placed by the inexperienced and unsuspect. ing. The consequences are serious : a young man attends classes, which he is led to believe qualify for the Naval Board, but who, upon his making application at the Admiralty, is iaformed that such tickets are not recognised by that department. His hopes are thus blighted in an instant-hopes which accompanied him day after day, caused him to exert himself, spurred him on in his studies, and made him oft-times 'trim the midnight lamp.' He must attend classes else where for another session, or give up all thought of entering the public service." $\mathrm{He}$ trusts that his complaint may be " a hint to those who are engaged in the study of medicine to look sharply around them, and not allow themselves to be imposed upon by men of such principle as these lecturers."

\section{TO CORRESPONDENTS.}

$M r . J . G$. writes to us in expostulation with the author of some recent remarks on the medical officers of St. George's Hospital. Mr. G. takes the opportunity of saying some very agreeable things on behalf of the courteous demeanour of one of them in consultation; but we are quite sure that the proper effect of Dr. H.'s manners and good breeding amongst his brethren in the profession, will be produced where they have the opportunity of being manifested, without any advertisement of them in our pages. Dr. H. will, nevertheless, be equally obliged to Mr. G.

W. M.S. It would not be " recognised" at either institution.

The paper " on the prevention of smallpox pits" shall appear in our next.

Communications have been received from N. H.; Mr. Robert Stevens; Mr. Rets; A Pupil of the London Hospital ; Mr. Lloyd.

'The insertion of the letter of "Another Student of St. George's" is anticipated in the letier upon the same subject, published in our preseut Number.

Dr. Weatherill's communication shall ap. pear in our next.

The letter of a "Student of St. George"s" is too long, and tos diffuse for our pages. 